\title{
Family Planning Services: An Essential Component of Preconception Care
}

\author{
Lorraine V. Klerman
}

Published online: 1 July 2006

(C) Springer Science+Business Media, Inc. 2006

\begin{abstract}
Family planning services are necessary for the widespread adoption of preconception care for two reasons. First, preconception care is more likely if pregnancies are planned, and family planning services encourage pregnancy planning. Second, family planning services usually include counseling, and counseling provides an opportunity to discuss the advantages of preconception care. However, the potential of family planning services to promote preconception care is limited by underutilization of these services and inadequate attention to preconception care during family planning visits. This article suggests ways to reduce these problems.
\end{abstract}

Keywords Family planning · Preconception care .

Pregnancy $\cdot$ Intendedness $\cdot$ Access

If all women of reproductive age, or at least those at elevated risk, are to benefit from preconception services, the use of family planning services must be increased and the content of such services expanded. Family planning services are essential for preconception care for at least two reasons. First, in the absence of such services, pregnancies will occur that have not benefited from preconception care. Preconception care during the reproductive years is dependent on women and men planning their pregnancies, not only in respect to their timing but also to healthrelated factors that would maximize the chances for a healthy pregnancy and a healthy infant. In the absence of such care, offered by family planning services, many pregnan-

L. V. Klerman $(\bowtie)$

Institute for Child, Youth and Family Policy, The Heller School

for Social Policy and Management, Brandeis University,

Mailstop 035, PO Box 549110, Waltham, MA 02454-9110

e-mail: klerman@brandeis.edu cies will not benefit from preconception advice. Second, family planning counseling provides an opportunity for promoting and providing preconception care. At the same time women and their partners are receiving advice about family planning, they can also receive instruction about the range of activities that lead to healthy pregnancies and healthy infants.

Unfortunately, several factors prevent family planning from reaching its maximal potential for preconception care. These include underutilization of family planning services and inadequate attention to preconception counseling during family planning visits.

\section{Underutilization of family planning services}

Two types of data point to underutilization of family planning services with implications for decreasing opportunities for preconception care: the percentage of women actually seeking family planning services and the percentage of unintended pregnancies.

Visits for family planning

The 2002 National Survey of Family Growth (NSFG) reported that $41.7 \%$ of women 15 to 44 years of age received at least one family planning service from a medical care provider in the 12 months prior to the interview [1]. This percentage is not as alarming as it might appear at first glance, because some of the women who did not seek family planning services already were pregnant, seeking to become pregnant, or infertile because of sterilization or other reasons. Nevertheless, this rather low percentage suggests that some women are not planning their pregnancies either deliberately 
or because they are experiencing problems obtaining family planning services.

\section{Pregnancy planning}

It is undoubtedly true that some women do not wish to plan the timing of their pregnancies. In many cases, these are married women who have religious objections to family planning. In Women of Crisis, one woman states “you don't think of life that way - of having children that way. You don't sit down and say you can afford to have a certain number of boys and girls; you have your children and try to do the best you can to be a good parent" [2]. This attitude is probably not widely held, rather most women and their partners have some preferences in terms of the timing of births. This may be expressed in terms of age, marital status, or attainment of some educational, career, or economic goal. Despite this, a large percentage of pregnancies are unintended, including those that were experienced earlier than wanted (mistimed) or those that were not wanted at the time they occurred or at any future time (unwanted).

According to the 2002 NSFG, $30.8 \%$ of all women 15 to 44 years of age had experienced an unintended birth at some time in their lives and, in the five years before the survey, $20.8 \%$ had had a mistimed birth and $14.1 \%$ an unwanted birth [3]. Using data from the 1982, 1988, and 1985 NSFGs, as well as abortion data, Henshaw estimated that in 1994, $49.2 \%$ of all pregnancies were unintended [4]. Employing a different set of questions to assess wantedness, the Pregnancy Risk Assessment Monitoring System (PRAMS) noted that in 1999 the percentage of unintended pregnancies resulting in live birth ranged from $33.7 \%$ to $52 \%$ across the 17 reporting states [5].

Although the relationship between use of a family planning method and pregnancy planning is sometimes tenuous an analysis of the 1995 NSFG found that $30.9 \%$ of the women who stated that their pregnancies had resulted from a contraceptive failure nevertheless classified the pregnancy as intended [6]. These data suggest that if preconception care were to be practiced widely, a larger percentage of women will need to seek family planning services to avoid unplanned pregnancies.

\section{Reasons for underutilization}

Many reasons have been suggested for the underutilization of family planning services, including cost, availability, and limited contraceptive methods $[7,8]$.

\section{Financial issues}

The possible patient payment sources for family planning services include private health insurance, Medicaid, or out- of-pocket payments. The March 2005 Current Population Survey found $24.5 \%$ of women 18 to 20 years of age, $30.6 \%$ of those 21 to $24,21.8 \%$ of those 25 to 34 , and $17.1 \%$ of those 35 to 44 to be uninsured [9]. If these uninsured women want to receive family planning services, they must rely on their own funds or seek care from facilities that provide services free of charge or on a sliding fee scale. These include publicly supported facilities such as health department family planning clinics, community health centers and public hospitals, and facilities that combine public and private funding sources, such as Planned Parenthood centers, women's clinics, school-based health centers, and not-forprofit hospitals. Public funds for family planning services in such facilities come primarily from Medicaid and Title $\mathrm{X}$ (the family planning act). These funds are inadequate to meet the need. For women whose eligibility is due to a pregnancy, eligibility for all medical services, including family planning, ends 60 days postpartum, except in states with a waiver to extend the period. Title $\mathrm{X}$ tries to fill in the gaps in coverage but it is chronically underfunded. Even for those with employer-based health insurance, coverage for family planning services is not universal. In 2003, $93 \%$ of health plans offered an annual ob/gyn visit, $88 \%$ covered oral contraceptives; $87 \%$, sterilization; and $72 \%$, all five reversible contraceptives. HMOs were more likely to offer contraceptives and sterilization than conventional plans, PPOs or POSs [10].

\section{Availability}

Family planning facilities need to be easily available both physically and psychologically. This means that they should be located where they can be reached easily by private or public transportation, be open days and hours that are convenient for potential users, offer the full range of contraceptive methods, provide educational materials in the languages of their patients, and employ personnel who can speak the language of the users and whose attitudes and behaviors are warm, friendly, and culturally sensitive. A recent four-state survey found that distance to a publicly financed family planning facility was not associated with teen or unintended pregnancies, suggesting that geographic availability is no longer a problem for family planning facilities [11], although it still is for abortion services [12]. The same study found major differences in terms of the other availability factors, such as limited hours, few contraceptive choices, and lack of translators [13]. Such problems may be partially responsible for inadequate contraceptive use.

\section{Limited contraceptive methods}

Although the number of family planning methods has increased in the past few decades, many women and men have 
difficulty finding one with which they are comfortable. The 2002 NSFG gave respondents a list of 19 family planning methods from which to choose. Among women 15-44 years of age, $61.9 \%$ currently were using a contraceptive method: the pill-18.9\%; female sterilization- $16.7 \%$ and the condom$11.1 \%$. About $4 \%$ were using the least effective methods, including periodic abstinence and withdrawal. Among women who had intercourse in the three months before the interview and who were not sterile, pregnant, postpartum, or seeking pregnancy, $7.4 \%$ were not using a contraceptive - an increase from the $5.2 \%$ in the 1995 NSFG. (Of those at risk for an unintended pregnancy, $89.3 \%$ were currently using a method.) [1]. It is important to recognize that contraceptive use data are based on self-reports and provide no indication of how consistently or correctly the methods are being used. Failure rates are high possibly because of inconsistent or improper use. In one study of the 1995 NSFG, $9 \%$ of women experienced a contraceptive failure within one year of starting to use a reversible method of contraception: $7 \%$ of those on the pill, $9 \%$ of those relying on a male condom, and $19 \%$ of those practicing withdrawal [14].

After female or male sterilization, hormonal methods are considered the most reliable form of contraception, but many women remain concerned about their safety. The side effects of many hormonal methods, especially Depo-Provera, discourage many women from their use [7, 8]. Further, the need to take a pill daily even in the absence of frequent intercourse creates problems for many women. Finally, the absence of a male contraceptive other than sterilization and the condom is a major barrier to effective and ongoing contraception.

The availability of one effective family planning method, emergency contraception (meant as back-up protection, not as a primary method), is currently limited by the refusal of the federal Food and Drug Administration to allow it to be sold over the counter and by the refusal of some pharmacists to fill prescriptions for this medication.

\section{Inadequate attention to preconception counseling}

Research is just beginning on the availability of preconception care overall although certain conditions, such as folic acid supplementation and counseling of diabetic women, have been studied extensively. The little existing evidence suggests that preconception care is not routinely integrated into family planning services, whether provided by obstetricians or family medicine specialists in private practice or HMOs, or by personnel in family planning facilities $[15,16]$. Under such circumstances, the potential of this service delivery system for improving pregnancy and infant health through preconception care is not yet being realized.

\section{Approaches to increasing utilization}

Several evaluations indicate that the utilization of family planning services can be increased. California's Family Planning, Access, Care, and Treatment Program (Family Pact) provided contraceptive services to low income, medically indigent women increased use and reduced the numbers of unintended pregnancies [17]. State family planning waivers that expand Medicaid coverage for women beyond the 60 day postpartum limit have had a similar impact [18, 19]. Programs such as these should be expanded to more states, but they address only financial barriers. Attention should also be paid to other access-related problems, such as hours and days that facilities are open and language problems. Additional outreach also needs to be directed to low literacy and immigrant populations [20].

\section{Approaches to improving content}

Moos [15] reviewed many of the activities that will be essential if preconception care is to be integrated into health care generally. The American College of Obstetrics and Gynecology recently published a Committee Opinion, "The Important of Preconception Care in the Continuum of Women's Heath Care" [21]. Here the focus is on adding preconception counseling to visits for family planning. The recent publication by the Centers for Disease Control and Prevention of "Recommendations to Improve Preconception Health and Health Care - United States" [22] should also lead to more and better preconception counseling.

In all likelihood, it may be most difficult to change patterns of family planning practice among physicians in private practice. In contrast, those in HMOs have the potential for exposure to more education about the need for such counseling. The establishment of standards for family planning services by the Health Plan Employer Data and Information Set (HEDIS) might also accelerate change. However, standard setting and financial and other incentives may be most effective when used with community health centers and health department and other publicly-funded sites of family planning services - as the women who use seek family planning at these sites may be those most in need of preconception care. Because such sites are funded by federal, state, and local governments, these units can insist that preconception care be integrated into their family planning services.

\section{Conclusions}

Progress towards preconception care for all women will only be possible if a larger percentage of women and men plan their pregnancies. At present, although visits for 
contraceptive advice and methods provide an excellent opportunity for counseling about ways to achieve healthy pregnancies and healthy infants through preconception care, this potential is not being achieved. Increased use of family planning and increased attention to preconception care within family planning services may require that additional resources be devoted to public and professional education and to service delivery standards and financing.

\section{References}

1. Mosher WD, Martinez GM, Chandra A, Abma JC, Willson SJ. Use of Contraception and Use of Family Planning Services in the United States, 1982-2002. Adv Data Vital Health Stat 2004;350:136.

2. Coles R, Coles JH. Women of Crisis. Lives of Struggle and Hope. New York, NY: Dell Publishing Co., Inc.; 1978.

3. Chandra A, Martinez GM, Mosher WD, Abma JC, Jones J. Fertility, Family Planning, and Reproductive Health of U.S. Women: Data from the 2002 National Survey of Family Growth. Hyattsville, MD: National Center for Health Statistics; 2005 (DHHS Publication No. [PHS] 2006-1977).

4. Henshaw SK. Unintended Pregnancy in the United States. Fam Plann Perspect 1998;30:24-9 \& 46.

5. Beck LF, Morrow B, Lipscomb LE, Johnson CH, et al. Prevalence of Selected Maternal Behaviors and Experiences, Pregnancy Risk Assessment Monitoring System (PRAMS), 1999. MMWR 2002;51(SS02):1-26.

6. Trussell J, Vaughan B, Stanford J. Are All Contraceptive Failures Unintended Pregnancies? Evidence from the 1995 National Survey of Family Growth. Fam Plann Perspect 1999;31:246-7 \& 260.

7. Sable MR, Libbus MK, Chiu J-E. Factors affecting Contraceptive Use in Women Seeking Pregnancy Tests: Missouri, 1997. Fam Plann Perspect 2000;32:124-31.

8. Jones RK, Darroch JE, Henshaw SK. Contraceptive Use among U.S. Women having Abortions in 2000-2001. Perspect Sex Reprod Health 2002;34:294-303.

9. Employee Benefit Research Institute. Sources of Health Insurance and Characteristics of the Uninsured: Analysis of the March
205 Current Population Survey. Issue Brief no. 287, November 2005.

10. Kaiser Family Foundation/Health Research and Educational Trust. Employer Health Benefits. 2003 Annual Survey. 2003.

11. Goodman DC, Klerman LV, Johnson KA, Chang CH, Marth N. Geographic Access to Family Planning: Are More Facilities Needed? (Available from authors).

12. Henshaw SK, Finer LB. The Accessibility of Abortion Services in the United States, 2001. Perspect Sex Reprod Health 2003;35:1624.

13. Klerman LV, Johnson KA, Chang $\mathrm{CH}$, Wright-Slaughter $\mathrm{P}$, Goodman DC. Accessibility of Family Planning Services: Impact of Structural and Organizational Factors. (Available from authors).

14. Trussell J, Vaughan B. Contraceptive Failure, Method-Related Discontinuation and Resumption of Use: Results from the $1995 \mathrm{Na}-$ tional Survey of Family Growth. Fam Plann Perspect 1999;31:64$72 \& 93$.

15. Moos M-K. Preconceptional Health Promotion. Progress in Changing a Prevention Paradigm. J Perinat Neonat Nurs 2004;18:2-13.

16. Bernstein PS, Sanghvi T, Merkatz IR. Improving Preconception Care. J Reprod Med 2000;45:546-552.

17. Foster DG, Klaisle CM, Blum M, Bradsberry ME, Brindis CD, Stewart FH. Expanded State-Funded Family Planning Services: Estimating Pregnancies Averted by the Family PACT Program in California, 1997-1998. Am J Public Health 2004;94:13416.

18. Edwards J, Bronstein J, Adams K. Evaluation of Medicaid Family Planning Demonstrations. CNA Corporation. CMS Contract No. 752-2-415921, November 2003.

19. Gold RB. Doing More for Less: Study Says State Medicaid Family Planning Expansions are Cost-Effective. The Guttmacher Report on Public Policy 2004;7.

20. Sonenstein FL, Punja S, Scarcella CA. Future Directions for Family Planning Research: A Framework for Title X Family Planning Service Delivery Improvement Research. Washington, DC, Urban Institute; 2004.

21. American College of Obstetricians and Gynecologists. ACOG Committee Opinion number 313, September 2005. The Importance of Preconception Care in the Continuum of Women's Health Care. Obst Gynecol 2005;106:656-66.

22. Johnson K, Posner SF, Biermann J, et al. Recommendations to Improve Preconception Health and Health Care - United States. MMWR 55:RR-6, April 21, 2006. 